\title{
FAMILIAL JAUNDICE OF THE NEWBORN ASSOCIATED WITH HEPATOSTEATOSIS
}

\author{
BY \\ A. HOLZEL and N. SHER \\ From the University of Manchester and the Duchess of York's Hospital for Babies, Manchester
}

(RECEIVED FOR PUBLICATION MAY 28, 1951)

Jaundice in the neonatal period may be either present at birth or develop within the first few days of life. Since Levine and his colleagues demonstrated ten years ago the anti-Rh agglutinins in mothers of infants with icterus gravis, this form of jaundice, present at birth or developing within a few hours, has received a great deal of attention. Haemolytic disease of the newborn as a cause of icterus dominates diagnostic consideration, whereas congenital syphilis has lost in aetiological importance. Cirrhosis of the foetal liver has in rare cases been described as giving rise to jaundice at birth and leading to a fatal outcome within three to eight weeks. In addition, jaundice may be 'physiological ' or due to septicaemia (Buhl's and Winckel's diseases), obliteration of the bile ducts or, more rarely, acholuric jaundice.

Two cases of congenital jaundice in siblings are here reported in which the pathogenesis differs from those already mentioned and which, to our knowledge, has not been previously recorded in the literature.

\section{Case Reports}

Case 1. M.K. was a full term male baby, born on May 12, 1947, after a forceps delivery. The forceps were applied because of delay in the second stage. The baby cried at birth and was noted to be jaundiced. The birth weight was $9 \frac{1}{2} \mathrm{lb}$. The mother was 23 years of age, para 2. Her diet had been adequate. Her health was good apart from some vomiting which persisted throughout the pregnancy. She had had infective hepatitis at the age of 20 but had completely recovered and there were no residual symptoms. Her Wassermann reaction was negative and she was Rh-positive. She had had a miscarriage at four months in April, 1946, the cause of which was unknown.

The baby was put to the breast six hours after birth and sucked satisfactorily and passed meconium normally. He continued to thrive until the fifth day when the mother noticed the jaundice to be much deeper. He then began to vomit his breast feeds and was lethargic.
As a result of the continued vomiting and deepening jaundice, the mother sought medical advice and the baby was admitted to hospital on May 20, 1947, aged 8 days.

On clinical examination the baby was noted to be fairly well nourished and weighed $7 \mathrm{lb}$. $10 \mathrm{oz}$. having lost almost 2 lb. since birth. There was marked jaundice of the skin, conjunctivae and mucous membranes. The mouth was healthy, the abdomen was slightly distended, and there was a sero-sanguineous discharge from the umbilicus. The liver edge could be palpated in the right iliac fossa. The surface was hard, smooth and rather tender. The spleen was not palpable. There was a soft systolic murmur heard over the whole precordium. No abnormality was detected,in any of the other systems.

A diagnosis of sepsis due to omphalitis was made and the infant was treated with penicillin, 12,500 units intramuscularly three-hourly, and sulphamezathine $0.5 \mathrm{~g}$. four-hourly. A swab of the umbilical discharge grew coagulase positive Staphylococcus aureus. Vitamin K, $5 \mathrm{mg}$., was administered twice daily intramuscularly. The prothrombin level was $25^{\circ} \mathrm{o} . \mathrm{Hb}$. was $134^{\circ} \mathrm{o}$ (Haldane), i.e. 18.5 g. $\%$; a red cell count gave 5.97 million/c.mm. The fragility test showed haemolysis beginning at $0 \cdot 4^{\circ}$ o saline and complete at $0 \cdot 25 \%$. The baby was $R h$-positive and the Coombs test was negative. The urine showed considerable quantities of bile and urobilin. The liver function tests gave the following results:

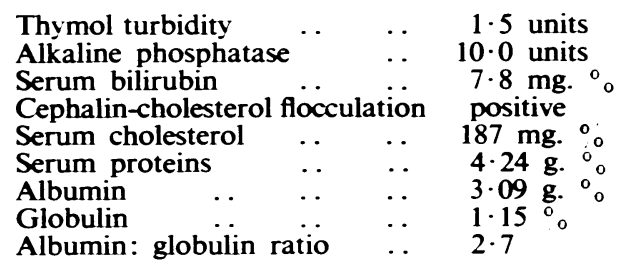

Attempts to perform the Wassermann test failed on two occasions owing to the fixation of complement in the absence of antigen.

During the next two days the jaundice gradually 
became more intense, and the infant's skin assumed an olive green colour suggesting obstructive jaundice. However, the stools remained well coloured and contained bile and bile pigments. Vomiting persisted. By May 26 the baby had become very irritable, and by May 31 the general condition had markedly deteriorated and the liver was palpable well into the pelvis. At this time another mass became palpable in the left loin which was thought to be the left kidney. The vomiting ceased and the mother was again allowed to feed the baby, but by June 12 her milk was insufficient and the infant was changed over to a half-cream dried milk formula.

He fed less satisfactorily, the jaundice became very intense, he became stuporous and then comatose and finally died on June 14 at the age of 31 days.

POST-MORTEM REPORT. The body was that of a small, wasted child with a markedly jaundiced skin.

There was no congenital abnormality of the heart and blood vessels. The ductus and foramen ovale were closed.

There were a few small consolidated areas near the apex of the right upper, lobe of the lung.

There was a slight excess of bile-stained fluid in the peritoneum. The stomach contained a fair amount of particles of altered blood; the contents of the large and small intestine were fhuid. The duodenal contents were deeply bile-stained.

The liver (300 g.) was grossly enlarged. It was bright yellow and homogeneous throughout except in the right lobe where there was a circumscribed area approximately $1.5 \times 1 \mathrm{~cm}$. which was of a lighter colour. The gall bladder was normal.

The spleen (18 g.) was slightly enlarged, dark and firm.

No abnormality was found in the adrenals, thyroid or thymus.

The kidneys (each $20 \mathrm{~g}$.) were normal.

The surface of the brain was rather flattened and unusually pale. Beneath the dura over the right parietal region there was a small amount of clotted blood. The brain tissue on section was unusually pale, and the distinction between cortex and medulla poor. Pus was present in both mastoid cavities.

Microscopical examination of a right mastoid swab showed a few pus cells and Gram-positive cocci (some in short chains). On culture a heavy growth of haemolytic streptococci and Staphylococcus aureus (coagulase positive) was seen. A left mastoid swab also showed pus cells and streptococci, and on culture a heavy growth of haemolytic streptococci with a few coliform organisms.

In the liver microscopical appearances were those of practically complete fatty change so that no normal liver cells were present, a scaffold of liver tissue and portal areas only remaining. There was no round cell or polymorphonuclear infiltration. The liver cells were grossly vacuolated as by fat. There was much bile pigment, some in the liver cells and some forming small plugs in the bile canaliculi. In the portal tracts there was extensive proliferation of the bile ducts and many of these contained bile plugs. The periportal fibrous tissue was increased and extended outwards though not sufficiently to merit the term cirrhosis.
No significant abnormality was seen in the kidney.

The solid areas noted in the lung were pneumonic. In the alveoli the infiltrated cells consisted of polymorphs with a considerable proportion of large mononuclear cells. The condition was more extensive than naked eye examination had suggested.

Case 2. S.K. was a full term male infant, born on May 22, 1950, after a spontaneous delivery. Birth weight was $8 \mathrm{lb}$. He cried immediately and was noticed to be markedly jaundiced at birth. No other abnormality was detected on clinical examination except enlargement of the liver.

The mother's age was now 26. Her health during this pregnancy had been good. Delivery was uneventful and anaesthesia was not required.

The infant was lethargic from birth and refused to suck when put to the breast. He began to vomit bile-stained fluid. By the second day of life the liver was palpable three finger breadths below the right costal margin. The surface was smooth and regular and the edge was sharp. The spleen was not palpated. The depth of the jaundice increased. Vomiting continued and on the third day thrush appeared on the tongue and buccal mucosa. He lost weight rapidly. The Wassermann reaction and Coombs test were negative, and the blood, which was Rh-positive, gave Hb. 125\% (Haldane), i.e. $17 \cdot 2$ g. $\%$; white cells 9,400 per c.mm. (polymorphs $63 \%$, lymphocytes $37 \%$ ).

The infant continued to vomit throughout the fourth day and his lethargy was much more marked. During the succeeding three days there was no improvement, the jaundice deepening further. He was increasingly sleepy but the liver remained the same size and consistency and the spleen was not palpable. By the eighth day his condition had further deteriorated. He had become comatose, the skin and mucous membranes were a deep yellow, the head was retracted, fists were clenched, and though the fontanelle tension was normal, a diagnosis of cerebral birth trauma was entertained. Lumbar puncture was performed and examination of the fluid, which was barely opalescent, gave red blood cells 40 per c.mm., polymorphs 1 per c.mm., protein $80 \mathrm{mg} . \%$, chlorides $770 \mathrm{mg} . \%$ and sugar $80 \mathrm{mg} . \%$.

The coma persisted and he died on June 3, 1950, aged 8 days.

POST-MORTEM REPORT. The body, that of a male child, was cyanosed and jaundiced. There were no other external abnormal findings.

The heart (40 g.) was of foetal shape, and the ductus arteriosus was widely patent. The orifices and valves were normal. The myocardium was pale but firm.

The left lung (40 g.) was completely atelectatic, and in the right lung $(60 \mathrm{~g}$.) there was considerable patchy collapse. Both pleural cavities contained blood-stained fluid, and the trachea and right bronchus were full of thick mucus.

The oesophagus, stomach and gut were normal. The liver (200 g.) was enlarged and a deep golden colour. The consistency was that of putty. The pattern was lost, and the bile ducts were patent. The pancreas and spleen were normal. 
Frg. 1.-Section of liver of M.K. showing complete fatty change.

FIG. 2.-Section of liver of S.K. showing destruction of normal liver tissue by deposits of fat.

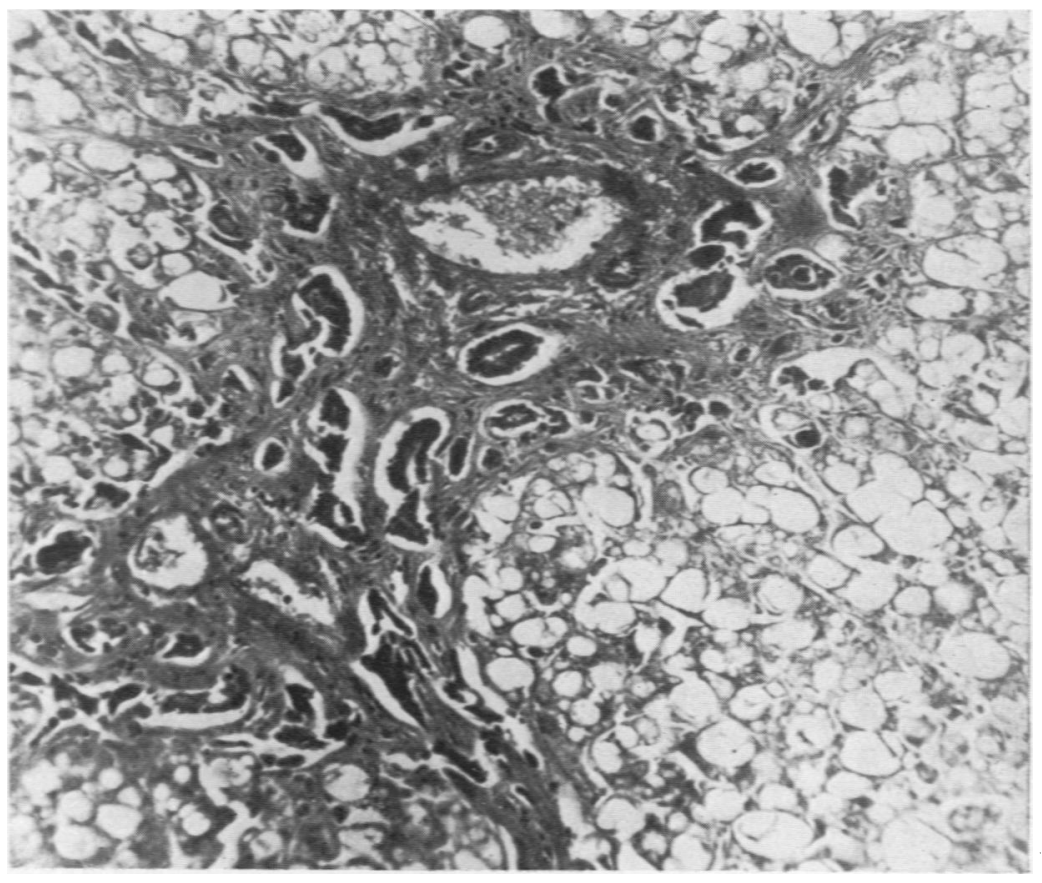


The kidneys (40 g. together) showed a swollen and yellowy cortex, of which the pattern was indistinct. The genital ducts, bladder and urethra were normal.

The brain, which was diffluent, was apparently normal.

Microscopically the liver showed extensive vacuolation of the cells, as by fat. Some pigmentation was present; near the portal tract it was probably formalin pigment. There was no increase in fibrous tissue or bile duct proliferation. Osmic acid and Sudan III staining of liver sections showed that the cells contained fat.

On special staining sections of the spleen and kidney showed no amyloid. Chemical analysis of the liver fat gave the following results:

$$
\begin{array}{llll}
\text { Total fat } & \ldots & \ldots & 17^{\circ} \text { (as total fatty acids) } \\
\text { Neutral fat } & \ldots & \ldots & 76^{\circ} \text { of total fat } \\
\text { Cholesterol } & \ldots & \ldots & 0 \cdot 88^{\circ} \text { 。 } \\
\text { Total phospholipids } & \ldots & 4 \cdot 2^{\circ},{ }^{\circ}
\end{array}
$$

\section{Discussion}

Fatty liver in the newborn has been encountered in Buhl's disease as part of the widespread fatty degeneration of parenchymatous organs in this condition, which is now commonly regarded as a form of neonatal septicaemia.

Haemorrhagic manifestations and severe asphyxia, leading to marked cyanosis and jaundice, are the outstanding manifestations of the clinical picture of Buhl's disease. With improved hygiene and care in maternity units and obstetric wards of hospitals it has become a rarity. The absence of asphyxia, cyanosis and haemorrhages differentiate it from the cases reported here. Jaundice may appear early in this condition but is not present at birth. Though Buhl's disease occurs sometimes in small epidemics it has not been reported in siblings.

Infection was present in the older of the siblings, but it appeared only after five days in the course of the primary illness and it is a fair assumption that this was superimposed, since delivery took place in the patient's home where hygiene may not have been adequate. The younger of the siblings, born in a modern maternity unit, did not show any signs of septicaemia or gross localized infection. Listlessness, failure to suck, inability to cry, jaundice and liver enlargement were evident from birth and have to be attributed to the single outstanding pathological finding, almost identical in both cases, hepatosteatosis.

The earliest report on the familial form of fatty liver as a cause of death in infancy was by Björum (1926) who described four cases in a family of 11 children. However, his cases differ in certain important aspects from those recorded here, in that jaundice was absent and none of his cases occurred in the neonatal period. The youngest was an infant who died at the age of 5 months and the oldest was 2 years. The liver was examined microscopically in the case of the 5-month-old infant and the cytoplasm of the liver cells was completely filled with fat. There were no changes in the nuclei but perhaps a slight increase in the interstitial tissue round the lobules.

In Britain Smith and O'Flynn (1933) presented two cases of familial hepatomegaly in a 6-year-old child and a 20-months-old infant. The six-year-old child had first come under observation at the age of 15 months. He was undersized, fat and flabby. The abdomen was enormously distended by the very large liver. He died suddenly after a bout of coughing. Jaundice was absent throughout his illness. At necropsy the liver was grossly enlarged, smooth, firm and pale buff. On sectioning, the cut surface appeared smooth and homogeneous with the exception of several minute yellow areas. On Scharlach-red staining the section showed large empty cells with preservation of the nucleus. No fat, lipoid or double refractive material was detected in the cells. Clearly this was not a case of fatty liver and the biochemical analysis of the liver (dried matter, $1 \cdot 202 \%$, cholesterol $0.728 \%$, cholesterol esters $0.060 \%$, fat and fatty acids $0.414 \%$ ) supports this opinion.

An interesting instance of hepatic steatosis was recorded by Debré and Semelaigne (1930) in an infant 9 months old who developed severe anorexia at the weaning period and in consequence suffered extreme loss of weight. The liver was grossly enlarged, and a small portion was removed for biopsy at laparotomy. On section most of the liver cells were seen to be invaded by large droplets of fat, the nuclei being compressed to one side. The portal spaces were the site of lymphoid infiltration. Signs of hepatic failure appeared at one stage, with the development of jaundice, purpura and urobilinuria, but finally the infant made a complete recovery.

Jaundice in the neonatal period, associated with hepatomegaly but not present at birth, has been reported in cases of galactosaemia by Bruck and Rapoport (1945), Göppert (1917), Goldbloom and Brickman (1946), Goldstein and Ennis (1948) and by Donnell and Lann (1951). But melituria, cataract, albuminuria and inanition help to mark it as a definite clinical entity. Hepatomegaly with marked steatosis occurs in von Gierke's disease but is not associated with severe congenital icterus, though a slight transitory jaundice may occur during the first month of life (Thannhauser, 1950).

Fatty liver in infancy is not an infrequent postmortem finding in children dying of toxic or infective conditions and chronic wasting diseases such as tuberculosis and diabetes. Massive steatosis in gastro-enteritis had been described by, among others, Marfan (1923), Marie, Seringe, Schweisguth 
and Hébert (1947) and Lévesque, Lafourcade and Demassieux (1947).

Fatty liver as a result or complication of severe forms of malnutrition has also been found in the infants and children of various tropical and subtropical countries. It is one of the outstanding pathological findings in kwashiorkor as encountered in West Africa, in the infantile pellagra as described in South Africa and studied by Gillman and Gillman (1945 $a$ and b). Waterlow (1948) investigated forms of malnutrition in the West Indies and refers to the condition as ' fatty liver disease', since fatty liver was regarded as the most important and dominating morbid anatomical observation. Similarly liver steatosis in undernourished children was reported from Chile by Meneghello, Niemeyer and Espinosa (1950). The large majority of the cases reported occurred after the first six months of life and usually in the second and third year. Jaundice is not a feature of the condition, which varies somewhat in its symptomatology according to its regional distribution, though marasmus, nutritional oedema and fatty liver seem manifestations common to all of them. However, none of the conditions described above appear to bear any relationship to the familial form of fatty liver in the neonatal period.

Waterlow (1948) found in chemical estimations of the fat content up to $50 \%$ of the fresh weight of the livers examined. A striking finding was the great increase in neutral fat. In Chile, Niemeyer and Iturra (1947) demonstrated an increase of total lipids to $20 \%$ of the net weight of the liver, most of the fat accumulated being formed by triglycerides. Phospholipids increased also but became stabilized at $4 \%$ and cholesterol at $1 \%$. Phospholipid values in Waterlow's cases ranged between $0.4 \mathrm{~g}$. and $2 \cdot 2 \mathrm{~g}$. per $100 \mathrm{~g}$. fat-free, dry weight.

Comparative data on the fat content of livers in normal and diseased children in Europe are scanty. The liver of an infant aged 5 days who died of cerebral haemorrhage was therefore also examined biochemically and the following figures were obtained:

$\begin{array}{llll}\text { Total fat } & \ldots & \ldots & 14^{\circ}{ }_{\circ} \text { (as total fatty acids) } \\ \text { Neutral fat } & \ldots & \ldots & 4 \cdot 5^{\circ}{ }^{\circ} \\ \text { Cholesterol } & \ldots & \ldots & 2 \cdot 1^{\circ}{ }^{\circ} \\ \text { Total phospholipids } & \ldots & 11 \cdot 3^{\circ}{ }^{\circ}\end{array}$

Thannhauser (1950) gives the following results for the fat analysis of the normal liver of an 8-monthsold infant:

$\begin{array}{llll}\text { Neutral fat } & \ldots & \ldots & 3 \cdot 4-3 \cdot 9^{\circ} \\ \text { Total cholesterol } & \ldots & \ldots & 0 \cdot 4-0 \cdot 6^{\circ}{ }^{\circ} \\ \text { Cholesterol esters } & \ldots & \ldots & 0 \cdot 1-0 \cdot 2^{\circ}{ }_{\circ}^{\circ} \\ \text { Free cholesterol } & \ldots & \ldots & 1 \cdot 19{ }^{\circ} \\ \text { Total phospholipids } & \ldots & \ldots & 5 \cdot 4-6 \cdot 3^{\circ} \\ \text { Fatty acids } & \ldots & \ldots & 7 \cdot 2-8 \cdot 5^{\circ}\end{array}$

This was compared with the fat analysis of liver in Case 2. The chief features are the increase in total fat, the high percentage of neutral fat and the low percentage of cholesterol and phospholipids.

Histologically there was a remarkable similarity in the appearance of the liver in both cases except that in Case 1 the process seemed to have progressed further. There was a complete disorganization of the liver structure, and indeed it was difficult to recognize the section as such. Only small areas of liver tissue were preserved and the function of the organ must have been severely impaired.

The maternal history did not reveal any dietary deficiency during pregnancy which might have suggested inadequate intake of the lipotropic factors. No drugs were administered or taken without advice, nor was there any evidence that the mother had suffered from poisoning with any of the substances that may induce fatty liver. Though she had chloroform anaesthesia for a short time during the birth of the first child, no use was made of an anaesthetic during delivery of the second. The possibility of a fat storage disease similar to gly cogen disease has therefore to be considered, be it due to absence of lipotropic factors or inhibition of certain enzyme systems. Whatever the pathogenesis, it must have affected the liver and its fat metabolism specifically, since both children developed in other respects normally in utero and had relatively high birth weights.

\section{Summary}

Two cases of jaundice present at birth occurring in the same family were reported.

Jaundice was associated and assumed to be due to marked hepatosteatosis which developed in utero.

Clinically the picture was that of jaundice at birth with gross liver enlargement, apathy, listlessness and anorexia leading to coma and death.

The chemical analysis of liver tissue showed an increase in the total fat, particularly of the neutral fat fractions $\left(76^{\circ}\right.$ ) with reduction in the phospholipids and cholesterol.

The relative literature is discussed and no previous reports of jaundice at birth due to fatty liver are traced.

Our thanks are due to Professor Wilfrid Gaisford for his interest and valuable criticism, to Dr. F. A. Langley and Dr. S. H. Jackson for the post-mortem and histological reports, to Dr. W. H. Patterson and Dr. M. L. Thomson for the loan of the notes of Case 1, and to Mr. H. Varley for the biochemical investigations.

\section{REFERENCES}

Björum, A. (1926). Acta paediatr., Stockh, 6, 225.

Bruck, E. and Rapoport, S. (1945). Amer. J. Dis. Child., 70, 267.

Debré. R. and Semelaigne, G. (1930). Pr. méd., 38, 1742 . 
Donnell, G. N. and Lann, S. H. (1951). Pediatrics, Marfan, A. B. (1923). 'Affections des Voies digestives Springfield, 7, 503. dans la première enfance.' Paris.

Gillman, T. and Gillman, J. (1945a). J. Amer. med. Marie, J., Seringe, P., Schweisguth, O. and Hébert, S. Ass., 129, 12. (1947). Arch. franç. Pédiat., 4, 389.

- - (1945b). Nature, Lond., 155, 634.

Goldbloom, A. and Brickman, H. F. (1946). J. Pediat., 28, 674.

Goldstein, E. O. and Ennis, J. M. (1948). Ibid., 33, $147-154$.

Göppert, F. (1917). Berlin. klin. Wschr., 54, 473.

Lévesque, J., Lafourcade, J. and Demassieux. (1947). Arch. frans. Pédiat., 4, 380.

Meneghello, J., Niemeyer, H. and Espinosa, J. (1950). Amer. J. Dis. Child., 80, 889.

Niemeyer, H. and Segismundo Iturra, T. (1947). Rev. chil. Pediat., 18, 141.

Smith, E. B. and Ö'Flynn, E. (1933). Lancet, 1, 297.

Thannhauser, S. J. (1950). 'Lipidoses,' 2nd ed., pp. 214, 316, 594. New York.

Waterlow, J. C. (1948). Spec. Rep. Ser. med. Res. Counc., Lond.. No. 263, pp. 14-15. 